\title{
Kontribusi Kekuatan Otot Lengan, Daya Tahan Otot Tungkai, Dan Koordinasi Mata Tangan Terhadap Kemampuan Passing Bawah Bolavoli
}

\section{Contribution of Arm Muscle Strength, Leg Muscle Endurance, and Eye Coordination To Volley Ball Underhand Pass Ability}

\author{
Sahabuddin*, Hikmad Hakim, Muslim \\ Program Studi Pendidikan Kepelatihan Olahraga, Fakultas Ilmu Keolahragaan, Universitas Negeri Makassar, \\ Jalan Wijaya Kusuma Raya No. 14 Makassar, Sulawesi Selatan, 90222, Indonesia \\ e-mail: sahabuddin@unm.ac.id, hikmad.hakim@unm.ac.id, muslim@unm.ac.id
}

\begin{abstract}
Abstrak
Penelitian ini bertujuan untuk mengetahui kontribusi kekuatan otot lengan, daya tahan otot tungkai, dan koordinasi mata tangan terhadap kemapmuan passing bawah dalam permainan bolavoli. Penelitian ini termasuk jenis penelitian deskriptif. Populasi penelitian ini adalah seluruh siswa laki-laki SMK Negeri 2 Watangsoppeng Kabupaten Soppeng dengan jumlah sampel penelitian 40 orang yang dipilih secara random sampling. Teknik analisis data yang digunakan adalah teknik analisis korelasi dengan menggunakan sistem SPSS Versi 22.00 pada taraf signifikan $95 \%$ atau $\alpha_{0,05}$. Bertolak dari hasil analisis data, maka penelitian ini menyimpulkan bahwa: (1) Kekuatan otot lengan memiliki kontribusi terhadap kemampuan passing bawah dalam permainan bolavoli pada siswa SMK Negei 2 Watang Soppeng Kabupaten Soppeng sebesar 53,8\%; (2) Daya tahan otot tungkai memiliki kontribusi terhadap kemampuan passing bawah dalam permainan bolavoli pada siswa SMK Negei 2 Watang Soppeng Kabupaten Soppeng sebesar 80,9\%; (3) Koordinasi mata tangan memiliki kontribusi terhadap kemampuan passing bawah dalam permainan bolavoli pada siswa SMK Negei 2 Watang Soppeng Kabupaten Soppeng sebesar 52,1\%; dan (4) Kekuatan otot lengan, daya tahan otot tungkai dan koordinasi mata tangan memiliki kontribusi terhadap kemampuan passing bawah dalam permainan bolavoli pada siswa SMK Negei 2 Watang Soppeng Kabupaten Soppeng sebesar $81,6 \%$.

Kata kunci: Kekuatan, Otot, Lengan, Daya Tahan, Tungkai, Koordinasi, Mata-Tangan, Passing Bawah, BolaVoli
\end{abstract}

\section{Abstract}

This study aims to determine the contribution of arm muscle strength, leg muscle endurance, and eye-hand coordination to the ability to underhand pass in volleyball. This research belongs to the type of descriptive research. The population of this study was all male students of SMK Negeri 2 Watangsoppeng, Soppeng Regency with a total sample of 40 people selected by random sampling. The data analysis technique used is the correlation analysis technique using the SPSS Version 22.00 system at a significant level of $95 \%$ or 0.05 . Based on the results of data analysis, this study concludes that: (1) Arm muscle strength has a contribution to the ability of underhand pass in volleyball games in students of SMK Negeri 2 Watang Soppeng, Soppeng Regency by 53.8\%; (2) Leg muscle endurance has a contribution to the ability to underhand pass in volleyball in SMK Negeri 2 Watang Soppeng students, Soppeng Regency by 80.9\%; (3) Eye-hand coordination has a contribution to the ability of underhand pass in the volleyball game in students of SMK Negeri 2 Watang Soppeng, Soppeng Regency by 52.1\%; and (4) arm muscle strength, leg muscle endurance and eye-hand coordination have a contribution to the ability of underhand pass in volleyball games in students of SMK Negeri 2 Watang Soppeng, Soppeng Regency by $81.6 \%$.

Keywords: Strength, Muscle, Arm, Endurance, Legs, Coordination, Eyes-Hands, Underhand Pass, Volleyball

corresponding author: sahabuddin@unm.ac.id

Artikel Info:

Submitted: 29/09/2021

Revised : 01/11/2021

Accepted : 09/11/2021

Published: 15/11/2021

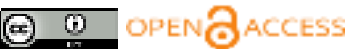

Journal Coaching Education Sports is licensed under a Creatives Commons Attribution 4.0 International License. 


\section{A. Pendahuluan}

Pendidikan jasmani dan kesehatan merupakan salah satu subsistem pendidikan yang wajib diajarkan di sekolah (Sahabuddin 2018), yang memiliki peran penting dalam pembentukan manusia seutuhnya. Pendidikan jasmani dan kesehatan merupakan bidang studi yang unik, karena melalui pendidikan jasmani seorang guru data mengembangkan kemampuan aspek kogitif, afektif, dan psikomotor serta sosial secara bersama-sama pada setiap peserta didik (Sahabuddin 2018). Pengajaran penjas harus dilakukan sejak dini (Mustaqim 2016), dengan demikian seorang guru diharapkan mampu mengajarkan berbagai keterampilan gerak, teknik, strategi dan mampu memodifikasi permainan dan olahraga (Ismoko and Sukoco 2013).

Dalam pembelajaran penjas di sekolah, olahraga merupakan suatu kebutuhan manusia untuk mendapatkan pendidikan dan kebugaran dalam hidupnya (Yudhianto and Hartati 2013). Ada tiga hal utama yang harus dilakukan dalam reformasi pendidikan, yaitu pembaharuan kurikulum, peningkatan kualitas pembelajaran, dan efektivitas metode pembelajaran (Sahabuddin, Hakim, and Bismar 2020). Program pendidikan harus komprehensif dan responsif terhadap dinamika sosial, relevan, dan mampu beradaptasi dengan keragaman kebutuhan dan kemajuan teknologi (Muhajir 2007).

Bolavoli merupakan salah satu olahraga yang paling digemari dan digemari oleh semua lapisan masyarakat, dimulai dari anak-anak, remaja, pria maupun wanita (Baidawi and Maidarman 2019). Terbukti bahwa permainan bolavoli ini dijadikan sebagai mata acara dalam pesta olahraga keramaian. Misalnya dalam kegiatan pertandingan di daerah-daerah, sekolahsekolah, maupun antar klub, olahraga bolavoli selalu jadi perhatian utama (Saputra 2018).

Permainan bolavoli merupakan cabang olahraga yang dapat dilatih secara optimal (Kastrena et al. 2020), jika pemain menguasai teknik dasar yang efektif dan efisien (Hambali 2019). Berbagai teknik dasar dalam bolavoli untuk dapat dimainkan, diantaranya: servis, passing (bawah dan atas), smash, dan blok. Untuk menampilkan teknik dasar tersebut tidak semudah yang dilihat. Setiap individu terlebih dahulu mengembangkan kemampuan fisik seperti: kekuatan, kecepatan, kelincahan, kelentukan, daya tahan, power dan lain-lain.

SMK Negeri 2 Watansoppeng misalnya, aktifitas ektrakurikuler terfokus pada pengembangan pembinaan olahraga bolavoli. Prestasi telah banyak diperoleh 
melalui pembinaan tersebut. Pertandingan antara sekolah se-Kabupaten Soppeng dipastikan selalu Juara. Dan siswa yang ada di SMK Negeri 2 Watansoppeng selalu mendominasi sebagai pemain yang ada di Kabupaten Soppeng. Ini menunjukkan bahwa cabang olahraga bolavoli di sekolah tersebut merupakan cabang olahraga favorit.

Aneka teknik dasar, teknik transmisi dasar merupakan teknik penting untuk belajar melakukan serangan (Haprabu 2017). Karena dua operan dalam permainan bolavoli (Kusnadi and Gani 2020), operan bawah lebih efektif untuk mengarahkan bola (Hamzah, Ginanjar, and Setiawan 2019).

Passing merupakan salah satu teknik dasar bola voli yang harus dikuasai oleh setiap pemain, karena teknik ini menurut (Jahrir 2019) adalah "salah satu teknik memainkan bola yang dilakukan oleh seorang pemain dengan satu atau dua tangan, dengan tujuan untuk mengarahkan bola kesuatu tempat atau teman regu untuk selanjutnya dimainkan kembali”. Saat bermain bolavoli, passing bawah khusus digunakan sebagai passing menyerang pertama (Afdi, Zulman, and Asmi 2019). Fitur khusus ini adalah cara yang efesien bagi pemain untuk mensmash dengan baik (Abrasyi et al. 2018). Selain manfaat utama yaitu pengenalan pukulan atau serangan yang berhasil (Ihwan 2011), pergerakan bola juga berperan dalam ritme permainan (Atsani 2020). Mengatur tempo permainan merupakan strategi untuk memenangkan pertandingan (Abrasyi et al. 2018).

Selain penguasaan teknik, kondisi fisik pemain sangat berperan penting dalam pencapaian prestasi olahraga (Pasaribu 2016). Juga dalam olahraga bola voli, pemain akan menonjol jika didukung oleh kondisi fisik yang baik (Satria 2019), karena kondisi fisik merupakan kapasitas fungsional dari sistem tubuh yang memungkinkan pemain mencapai prestasi yang lebih baik (Zakaria, Mudian, and Riyanto 2018). Komponen kesegaran jasmani meliputi daya tahan kardiovaskuler, daya tahan otot, kekuatan otot (strength), kelentukan (flexibility), kecepatan, stamina, kelincahan (agility), dan power (Sahabuddin 2019). Komponen-komponen kebugaran yang menunjang permainan bolavoli terutama pada saat menguasai teknik passing antara lain kekuatan otot lengan, daya tahan otot tungkai dan koordinasi mata tangan.

Kekuatan adalah kemampuan untuk mengembangkan kekuatan maksimal (Oktariana and Hardiyono 2020) dengan kontraksi yang maksimal untuk mengatasi resistensi atau stres (Hamid 2013). Sebagian besar pertunjukan olahraga 
melibatkan gerakan (Iskandar 2016) yang

disebabkan kemampuan kekuatan yang diciptakan kontraksi otot (Saptiani,

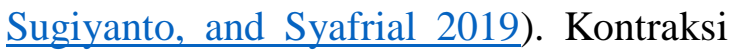
otot digunakan untuk menghasilkan tenaga internal (Iskandar 2016) yang mengatur gerakan bahagian-bahagian badan seperti pada otot lengan.

Daya tahan otot tungkai adalah kemampuan dalam mengantisipasi tingkat kelelahan (Hafiz Nursalam 2020) bagi setiap pemain atau siswa dalam melakukan gerakan-gerakan pada permainan bolavoli. Atau tingkat kemampuan siswa untuk dapat beraktivitas kembali tanpa merasakan kelelahan yang berarti setelah melaksanakan aktivitas, khususnya pada otot-otot tungkai (Hardiansyah 2019). Daya tahan otot tungkai menunjang gerak passing bawah untuk dapat mengantisipasi datangnya bola baik maupun saat posisi tungkai untuk dapat lebih rendah (setengah jongkok) agar bola yang dipassing akan lebih terarah dan akurat.

Koordinasi mata tangan merupakan gerak yang ditimbulkan akibat informasi di integrasikan dalam berbagai gerak pada tubuh (Masrun 2020). Pergerakan tangan dapat terkontrol secara visual yang disesuaikan urutan gerak terencana pada passing bawah bolavoli (Ikadarny and

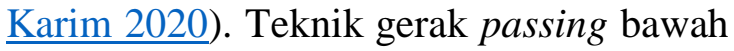
ataupun teknik lainnya dibutuhkan rangkaian input untuk dilihat (Juita 2013), input tersebut dimasukkan sebagai output ke dalam gerak motorik sehingga hasilnya adalah gerakan terkoordinasi yang fleksibel (Nasriani and Mardela 2019).

\section{B. Metode Penelitian}

Metode deksriptif secara korelasional menjadi metode pada penelitian ini. Tujuan dari metode ini adalah mendeskripsikan secara tersistematis, akurat dan objektif pada sumber data atau populasi. Fokus variabel dalam penelitian ada dua, yaitu: variabel bebas yaitu kekuatan otot lengan, daya tahan otot tungkai, dan koordinasi mata tangan, sedangkan variabel terikat yaitu kemampuan passing bawah. Rancangan penelitian yang digunakan adalah korelatif. Populasi penelitan ini yaitu siswa putra SMA Negeri 1 Marioriawa dengan jumlah sampel yang digunakan sebanyak 40 orang dari 120 orang siswa atau $30 \%$ populasi. Prosedur dalam memilih sampel yaitu sistem acak. Selanjutnya mengumpulkan data dari variabel yang terlibat pada penelitian. Data yang terkumpul tersebut perlu dianalisis secara statistik deskriptif, maupun inferensial secara korelasional dan regresi untuk keperluan pengujian hipotesis penelitian. Kemudian dianalisis melalui program aplikasi SPSS versi 22.00 dengan taraf signifikan $95 \%$ atau $\alpha_{0,05}$. 


\section{Hasil dan Pembahasan}

Hasil analisis deskriptif setiap variabel penelitian dapat dilihat dalam tabel 1 .

Tabel 1.

Hasil analisis deskriptif tiap variabel.

\begin{tabular}{|c|c|c|c|c|c|c|}
\hline & $\mathrm{N}$ & Sum & Mean & Stdv & Min & $\begin{array}{c}\mathrm{Ma} \\
\mathrm{x} .\end{array}$ \\
\hline $\begin{array}{l}\text { Kekuat } \\
\text { an otot } \\
\text { lengan }\end{array}$ & $\begin{array}{l}4 \\
0\end{array}$ & $\begin{array}{r}677, \\
00\end{array}$ & $\begin{array}{r}16,9 \\
250\end{array}$ & $\begin{array}{r}2,47 \\
436\end{array}$ & $\begin{array}{r}12, \\
00\end{array}$ & $\begin{array}{r}21, \\
00\end{array}$ \\
\hline $\begin{array}{l}\text { Daya } \\
\text { tahan } \\
\text { otot } \\
\text { tungka } \\
\text { i }\end{array}$ & $\begin{array}{l}4 \\
0\end{array}$ & $\begin{array}{r}1560 \\
, 00\end{array}$ & $\begin{array}{r}39,0 \\
000\end{array}$ & $\begin{array}{r}2,70 \\
801\end{array}$ & $\begin{array}{r}34 \\
00\end{array}$ & $\begin{array}{r}45 \\
00\end{array}$ \\
\hline $\begin{array}{l}\text { Koordi } \\
\text { nasi } \\
\text { mata } \\
\text { tangan }\end{array}$ & $\begin{array}{l}4 \\
0\end{array}$ & $\begin{array}{r}697, \\
00\end{array}$ & $\begin{array}{r}17,4 \\
250\end{array}$ & $\begin{array}{r}1,81 \\
005\end{array}$ & $\begin{array}{c}14 \\
00\end{array}$ & $\begin{array}{c}21, \\
00\end{array}$ \\
\hline $\begin{array}{l}\text { Passin } \\
g \\
\text { bawah } \\
\text { bolavo } \\
\text { li }\end{array}$ & $\begin{array}{l}4 \\
0\end{array}$ & $\begin{array}{r}329 \\
00\end{array}$ & $\begin{array}{r}8,22 \\
50\end{array}$ & $\begin{array}{r}1,79 \\
011\end{array}$ & $\begin{array}{r}5,0 \\
0\end{array}$ & $\begin{array}{r}12, \\
00\end{array}$ \\
\hline
\end{tabular}

Salah satu asumsi yang harus dipenuhi agar statistik parametrik dapat digunakan pada penelitian adalah data harus mengikuti sebaran normal. Untuk mengetahui sebaran data kekuatan otot lengan, daya tahan otot tungkai, koordinasi mata tangan, dan kemampuan passing bawah dalam permainan bolavoli pada siswa SMK Negeri 2 Watangsoppeng, maka dilakukan uji normalitas data dengan menggunakan Uji Kolmogorov Smirnov (KS-Z). Hasil data analisis dapat dilihat pada Tabel 2 berikut:
Tabel 2.

Hasil uji normalitas tiap variabel

\begin{tabular}{|l|c|c|c|c|}
\hline \multicolumn{1}{|c|}{ Variabel } & $\begin{array}{c}\text { K }- \\
\text { SZ }\end{array}$ & $\mathbf{P}$ & $\boldsymbol{\alpha}$ & Ket. \\
\hline $\begin{array}{l}\text { Kekuatan otot } \\
\text { lengan }\end{array}$ & 0,991 & 0,280 & 0,05 & Normal \\
\hline $\begin{array}{l}\text { Daya tahan otot } \\
\text { tungkai }\end{array}$ & 0,758 & 0,613 & 0,05 & Normal \\
\hline $\begin{array}{l}\text { Koordinasi mata } \\
\text { tangan }\end{array}$ & 1,008 & 0,261 & 0,05 & Normal \\
\hline $\begin{array}{l}\text { Passing bawah } \\
\text { bolavoli }\end{array}$ & 1,217 & 0,103 & 0,05 & Normal \\
\hline \multicolumn{4}{|c|}{ Berdasarkan tabel 2} & diatas \\
\hline
\end{tabular}

menunjukkan bahwa dari hasil pengujian normalitas data kekuatan otot lengan, daya tahan otot tungkai, koordinasi mata tangan, dan kemampuan passing bawah dalam permainan bolavoli menggunakan Uji Kolmogorov Smirnov menunjukkan hasil sebagai berikut:

a. Dalam pengujian normalitas data kekuatan otot lengan pada siswa SMK Negeri 2 Watangsoppeng diperoleh nilai uji Kolmogorov-Smirnov Test 0,991 dengan tingkat probabilitas $(\mathrm{P})$ 0,280 lebih besar dari pada nilai $\alpha_{0,05}$. Dengan demikian data kekuatan otot lengan pada siswa SMK Negeri 2 Watangsoppeng yang diperoleh mengikuti sebaran normal atau berdistribusi normal.

b. Dalam pengujian normalitas data daya tahan otot tungkai pada siswa SMK Negeri 2 Watangsoppeng diperoleh nilai uji Kolmogorov-Smirnov Test 
0,758 dengan tingkat probabilitas $(\mathrm{P})$ 0,613 lebih besar dari pada nilai $\alpha_{0,05}$. Dengan demikian data daya tahan otot tungkai pada siswa SMK Negeri 2 Watangsoppeng yang diperoleh mengikuti sebaran normal atau berdistribusi normal.

c. Dalam pengujian normalitas data koordinasi mata tangan pada siswa SMK Negeri 2 Watangsoppeng diperoleh nilai uji KolmogorovSmirnov Test 1,008 dengan tingkat probabilitas (P) 0,261 lebih besar dari pada nilai $\alpha_{0,05}$. Dengan demikian data koordinasi mata tangan pada siswa SMK Negeri 2 Watangsoppeng yang diperoleh mengikuti sebaran normal atau berdistribusi normal.

d. Dalam pengujian normalitas data kemampuan passing bawah dalam permainan bolavoli pada siswa SMK Negeri 2 Watangsoppeng diperoleh nilai uji Kolmogorov-Smirnov Test 1,217 dengan tingkat probabilitas (P) 0,103 lebih besar dari pada nilai $\alpha_{0,05}$. Dengan demikian data kemampuan passing bawah dalam permainan bolavoli pada siswa SMK Negeri 2 Watangsoppeng yang diperoleh mengikuti sebaran normal atau berdistribusi normal.

Untuk pengujian hipotesis tersebut maka dilakukan uji korelasi dan regresi data kekuatan otot lengan, daya tahan otot tungkai, koordinasi mata tangan dan kemampuan passing bawah dalam permainan bolavoli pada siswa SMK Negeri 2 Watangsoppeng.

\section{Ada kontribusi kekuatan otot lengan terhadap kemampuan passing \\ bawah dalam permainan bolavoli}

Hasil data yang diperoleh dari penelitian bertujuan untuk mengetahui antara variabel bebas dan variabel terikat serta membuktikan hipotesis yang ada. Oleh karena itu hasil pengujian hipotesis berdasarkan pengolahan data melalui analisis korelasi dan regresi dari program SPSS tentang kontribusi kekuatan otot lengan terhadap kemampuan passing bawah dalam permainan bolavoli pada siswa SMK Negeri 2 Watangsoppeng diperoleh sesuai rangkuman tabel 3 berikut:

Tabel 3.

Hasil analisis korelasi dan regresi untuk hipotesis pertama

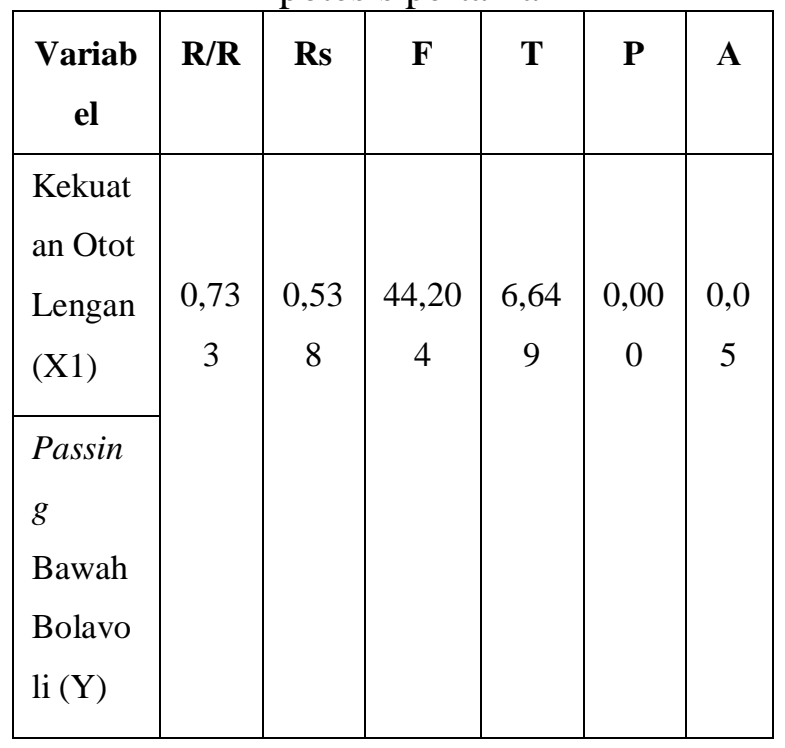


Hipotesis statistik yang akan di uji:

$\mathrm{H}_{0}: \mathrm{Rx}_{1 . \mathrm{y}}=0$

$\mathrm{H}_{1}: \mathrm{Rx}_{1 . \mathrm{y}} \neq 0$

Hasil pengujian:

Berdasarkan hasil pengujian analisis korelasi dan regresi data antara kekuatan otot lengan terhadap kemampuan passing bawah dalam permainan bolavoli pada siswa SMK Negeri 2 Watangsoppeng. Diperoleh nilai korelasi dan regresi 0,733 dengan tingkat probabilitas $(0,000)<\alpha_{0,05}$, untuk nilai $\mathrm{R}$ Square (koefesien determinasi) 0,538. Hal ini berarti 53,8\% kemampuan passing bawah dalam permainan bolavoli dijelaskan oleh kekuatan otot lengan. Dari uji Anova atau F test, didapat F hitung adalah 44,204 dengan tingkat signifikansi 0,000. Oleh karena probabilitas $(0,000)$ jauh lebih kecil dari $\alpha_{0,05}$, maka model regresi dapat dipakai untuk memprediksi kemampuan passing bawah dalam permainan bolavoli (dapat diberlakukan untuk populasi dimana sampel diambil). Dari uji t diperoleh 6,649 dengan tingkat signifikansi 0,000 . Oleh karena probabilitas $(0,000)$ jauh lebih kecil dari $\alpha_{0,05}$. Maka Ho ditolak dan $\mathrm{H}_{1}$ diterima atau koefesien regresi signifikan, atau kekuatan otot lengan benar-benar berpengaruh secara signifikan terhadap kemampuan passing bawah dalam permainan bolavoli.

Dengan demikian dapat disimpulkan bahwa kontribusi kekuatan otot lengan terhadap kemampuan passing bawah dalam permainan bolavoli pada siswa SMK Negeri 2 Watangsoppeng sebesar $53,8 \%$.

\section{Ada kontribusi daya tahan otot} tungkai terhadap kemampuan passing bawah dalam permainan bolavoli

Hasil data yang diperoleh dari penelitian bertujuan untuk mengetahui antara variabel bebas dan variabel terikat serta membuktikan hipotesis yang ada. Oleh karena itu hasil pengujian hipotesis berdasarkan pengolahan data melalui analisis korelasi dan regresi dari program SPSS tentang kontribusi daya tahan otot tungkai terhadap kemampuan passing bawah dalam permainan bolavoli pada siswa SMK Negeri 2 Watangsoppeng diperoleh sesuai dari rangkuman tabel 4 berikut:

Tabel 4.

Hasil analisis korelasi dan regresi untuk hipotesis kedua

\begin{tabular}{|c|c|c|c|c|c|c|}
\hline $\begin{array}{c}\text { Varia } \\
\text { bel }\end{array}$ & $\mathbf{R} / \mathbf{R}$ & Rs & $\mathbf{F}$ & $\mathbf{T}$ & $\mathbf{P}$ & $\mathbf{A}$ \\
\hline Daya & \multirow{8}{*}{$\begin{array}{c}0,89 \\
9\end{array}$} & \multirow{8}{*}{$\begin{array}{c}0,80 \\
9\end{array}$} & \multirow{8}{*}{$\begin{array}{c}160,4 \\
89\end{array}$} & \multirow{8}{*}{$\begin{array}{c}12,6 \\
68\end{array}$} & \multirow{8}{*}{$\begin{array}{c}0,00 \\
0\end{array}$} & \multirow{8}{*}{$\begin{array}{r}0,0 \\
5\end{array}$} \\
\hline Tahan & & & & & & \\
\hline Otot & & & & & & \\
\hline Tungk & & & & & & \\
\hline ai $(\mathrm{X} 2)$ & & & & & & \\
\hline Passin & & & & & & \\
\hline$g$ & & & & & & \\
\hline Bawah & & & & & & \\
\hline
\end{tabular}




\begin{tabular}{|c|c|c|c|c|c|c|}
\hline $\begin{array}{c}\text { Varia } \\
\text { bel }\end{array}$ & R/R & Rs & F & T & P & A \\
\hline $\begin{array}{l}\text { Bolavo } \\
\text { li (Y) }\end{array}$ & & & & & & \\
\hline
\end{tabular}

Hipotesis statistik yang akan di uji:

$$
\begin{aligned}
& \mathrm{H}_{0}: \mathrm{Rx}_{2 . \mathrm{y}}=0 \\
& \mathrm{H}_{1}: \mathrm{Rx}_{2 . \mathrm{y}} \neq 0
\end{aligned}
$$

Hasil pengujian:

Berdasarkan hasil pengujian analisis korelasi dan regresi data antara daya tahan otot tungkai terhadap kemampuan passing bawah dalam permainan bolavoli pada siswa SMK Negeri 2 Watangsoppeng. Diperoleh nilai korelasi dan regresi 0,899 dengan tingkat probabilitas $(0,000)<\alpha_{0,05}$, untuk nilai $\mathrm{R}$ Square (koefesien determinasi) 0,809 . Hal ini berarti $80,9 \%$ kemampuan passing bawah dalam permainan bolavoli dijelaskan oleh daya tahan otot tungkai. Dari uji Anova atau F test, didapat $\mathrm{F}$ hitung adalah 160,489 dengan tingkat signifikansi 0,000 . Oleh karena probabilitas $(0,000)$ jauh lebih kecil dari $\alpha_{0,05}$, maka model regresi dapat dipakai untuk memprediksi kemampuan passing bawah dalam permainan bolavoli (dapat diberlakukan untuk populasi dimana sampel diambil). Dari uji-t diperoleh 12,668 dengan tingkat signifikansi 0,000 . Oleh karena probabilitas $(0,000)$ jauh lebih kecil dari $\alpha_{0,05}$. Maka Ho ditolak dan $\mathrm{H}_{1}$ diterima atau koefesien regresi signifikan, atau daya tahan otot tungkai benar-benar berpengaruh secara signifikan terhadap kemampuan passing bawah dalam permainan bolavoli.

Dengan demikian dapat disimpulkan bahwa kontribusi daya tahan otot tungkai terhadap kemampuan passing bawah dalam permainan bolavoli pada siswa SMK Negeri 2 Watangsoppeng sebesar 80,9\%.

\section{Ada kontribusi koordinasi mata tangan terhadap kemampuan passing bawah dalam permainan bolavoli}

Hasil data yang diperoleh dari penelitian bertujuan untuk mengetahui antara variabel bebas dan variabel terikat serta membuktikan hipotesis yang ada. Oleh karena itu hasil pengujian hipotesis berdasarkan pengolahan data melalui analisis korelasi dan regresi dari program SPSS tentang kontribusi koordinasi mata tangan terhadap kemampuan passing bawah dalam permainan bolavoli pada siswa SMK Negeri 2 Watangsoppeng diperoleh sesuai dari rangkuman tabel 5 berikut:

\section{Tabel 5.}

Hasil analisis korelasi dan regresi untuk

\begin{tabular}{|c|c|c|c|c|c|c|}
\hline Variabel & $\mathbf{R} / \mathbf{R}$ & Rs & $\mathbf{F}$ & $\mathbf{T}$ & $\mathbf{P}$ & $\mathbf{A}$ \\
\hline $\begin{array}{l}\text { Koordina } \\
\text { si Mata } \\
\text { Tangan } \\
\text { (X3) }\end{array}$ & \multirow[t]{2}{*}{$\begin{array}{c}0,72 \\
2\end{array}$} & \multirow[t]{2}{*}{$\begin{array}{c}0,52 \\
1\end{array}$} & \multirow[t]{2}{*}{$\begin{array}{c}41,26 \\
1\end{array}$} & \multirow[t]{2}{*}{$\begin{array}{c}6,42 \\
4\end{array}$} & \multirow[t]{2}{*}{$\begin{array}{c}0,00 \\
0\end{array}$} & \multirow[t]{2}{*}{0,05} \\
\hline $\begin{array}{l}\text { Passing } \\
\text { Bawah } \\
\text { Bolavoli } \\
\text { (Y) }\end{array}$ & & & & & & \\
\hline
\end{tabular}
hipotesis ketiga

Hipotesis statistik yang akan di uji: 


$$
\begin{aligned}
& \mathrm{H}_{0}: \mathrm{Rx}_{3 . \mathrm{y}}=0 \\
& \mathrm{H}_{1}: \mathrm{Rx}_{3 . \mathrm{y}} \neq 0
\end{aligned}
$$

Hasil pengujian:

Berdasarkan hasil pengujian analisis korelasi dan regresi data antara koordinasi mata tangan terhadap kemampuan passing bawah dalam permainan bolavoli pada siswa SMK Negeri 2 Watangsoppeng. Diperoleh nilai korelasi dan regresi 0,722 dengan tingkat probabilitas $(0,000)<\alpha$ 0,05, untuk nilai $\mathrm{R}$ Square (koefesien determinasi) 0,521. Hal ini berarti 52,1\% kemampuan passing bawah dalam permainan bolavoli dijelaskan oleh koordinasi mata tangan. Dari uji Anova atau $\mathrm{F}$ test, didapat $\mathrm{F}$ hitung adalah 41,261 dengan tingkat signifikansi 0,000. Oleh karena probabilitas $(0,000)$ jauh lebih kecil dari $\alpha_{0,05}$, maka model regresi dapat dipakai untuk memprediksi kemampuan passing bawah dalam permainan bolavoli (dapat diberlakukan untuk populasi dimana sampel diambil). Dari uji-t diperoleh 6,424 dengan tingkat signifikansi 0,000 . Oleh karena probabilitas $(0,000)$ jauh lebih kecil dari $\alpha_{0,05}$. Maka Ho ditolak dan $\mathrm{H}_{1}$ diterima atau koefesien regresi signifikan, atau koordinasi mata tangan benar-benar berpengaruh secara signifikan terhadap kemampuan passing bawah dalam permainan bolavoli.

Dengan demikian dapat disimpulkan bahwa kontribusi koordinasi mata tangan terhadap kemampuan passing bawah dalam permainan bolavoli pada siswa SMK Negeri 2 Watangsoppeng sebesar 52,1\%.

\section{Ada kontribusi kekuatan otot} lengan, daya tahan otot tungkai, dan koordinasi mata tangan terhadap kemampuan passing bawah dalam permainan bolavoli

Hasil data yang diperoleh dari penelitian bertujuan untuk mengetahui antara variabel bebas dan variabel terikat serta membuktikan hipotesis yang ada. Oleh karena itu hasil pengujian hipotesis berdasarkan pengolahan data melalui analisis regresi dari program SPSS tentang hubungan antara kekuatan otot lengan, daya tahan otot tungkai, dan koordinasi mata tangan terhadap kemampuan passing bawah dalam permainan bolavoli pada siswa SMK Negeri 2 Watangsoppeng diperoleh sesuai dari rangkuman tabel 6 berikut:

Tabel 6.

Hasil analisis regresi untuk hipotesis

\begin{tabular}{|c|c|c|c|c|c|c|}
\hline $\begin{array}{c}\text { VARIABE } \\
\text { L }\end{array}$ & $\mathbf{r} / \mathbf{R}$ & Rs & $\mathbf{F}$ & $\mathbf{t}$ & $\mathbf{P}$ & $\alpha$ \\
\hline $\begin{array}{l}\text { Kekuatan } \\
\text { otot lengan } \\
\text { (X1), daya }\end{array}$ & \multirow{3}{*}{$\begin{array}{c}0,90 \\
3\end{array}$} & \multirow[t]{3}{*}{0,816} & \multirow{3}{*}{$\begin{array}{c}53,21 \\
5\end{array}$} & \multirow[t]{3}{*}{6,960} & \multirow{3}{*}{$\begin{array}{c}0,00 \\
0\end{array}$} & \multirow[t]{3}{*}{0,05} \\
\hline $\begin{array}{l}\text { tahan otot } \\
\text { tungkai } \\
\text { (X2), dan } \\
\text { koordinasi } \\
\text { mata } \\
\text { tangan } \\
\text { (X3) }\end{array}$ & & & & & & \\
\hline $\begin{array}{l}\text { Passing } \\
\text { bawah } \\
\text { bolavoli } \\
\text { (Y) }\end{array}$ & & & & & & \\
\hline
\end{tabular}
keempat 
Hipotesis statistik yang akan di uji:

$\mathrm{H}_{0}: \mathrm{Rx}_{1.2 .3 . \mathrm{y}}=0$

$\mathrm{H}_{1}: \mathrm{Rx}_{1.2 .3 . \mathrm{y}} \neq 0$

Hasil pengujian:

Berdasarkan hasil pengujian analisis regresi data antara kekuatan otot lengan, daya tahan otot tungkai, dan koordinasi mata tangan terhadap kemampuan passing bawah dalam permainan bolavoli pada siswa SMK Negeri 2 Watangsoppeng. Diperoleh nilai regresi 0,903 dengan tingkat probabilitas $(0,000)<\alpha_{0,05}$, untuk nilai R Square (koefesien determinasi) 0,816. Hal ini berarti $81,6 \%$ kemampuan passing bawah dalam permainan bolavoli dijelaskan oleh kekuatan otot lengan, daya tahan otot tungkai, dan koordinasi mata tangan. Dari uji Anova atau F test, didapat F hitung adalah 53,215 dengan tingkat signifikansi 0,000 . Oleh karena probabilitas $(0,000)$ jauh lebih kecil dari $\alpha_{0,05}$, maka model regresi dapat dipakai untuk memprediksi kemampuan passing bawah dalam permainan bolavoli (dapat diberlakukan untuk populasi dimana sampel diambil). Dari uji-t diperoleh 6,960 dengan tingkat signifikansi 0,000 . Oleh karena probabilitas $(0,000)$ jauh lebih kecil dari $\alpha_{0,05}$. Maka Ho ditolak dan $\mathrm{H}_{1}$ diterima atau koefesien regresi signifikan, atau kekuatan otot lengan, daya tahan otot tungkai, dan koordinasi mata tangan benarbenar berpengaruh secara signifikan terhadap kemampuan passing bawah dalam permainan bolavoli.

Dengan demikian dapat disimpulkan bahwa kontribusi kekuatan otot lengan, daya tahan otot tungkai, dan koordinasi mata tangan terhadap kemampuan passing bawah dalam permainan bolavoli pada siswa SMK Negeri 2 Watangsoppeng sebesar $81,6 \%$.

\section{Pembahasan}

Hasil analisis data melalui teknik statistik diperlukan pembahasan teoritis yang bersandar pada teori dan kerangka berpikir yang mendasari penelitian.

\section{Ada kontribusi kekuatan otot lengan terhadap kemampuan passing \\ bawah dalam permainan bolavoli}

Hasil analisis statistik menunjukkan bahwa ada kontribusi kekuatan otot lengan terhadap kemampuan passing bawah dalam permainan bolavoli pada siswa SMK Negeri 2 Watangsoppeng. Apabila hasil penelitian dikaitkan dengan teori dan kerangka pikir yang mendasarinya, maka dalam dasarnya hasil penelitian ini mendukung dan memperkuat teori dan hasil-hasil penelitian terdahulu yang sudah ada. Ini membuktikan bahwa kekuatan pada otot-otot lengan harus dimiliki bagi pemain bolavoli. Kekuatan otot lengan berfungsi sebagai penggerak dalam melaksanakan passing bawah. Gerakan pantulan bola akan terjadi dengan baik bila lengan yang dimiliki seorang pemain ditopan adanya kemampuan fisik kekuatan 
Sahabuddin, Hikmad Hakim, Muslim

(Nurudin 2015). Pola gerak dalam passing bawah yaitu pantulan bola yang dibangun pada dasarnya harus parabola, hal ini dilakukan untuk mendapatkan umpan yang lebih baik dari orang kedua atau lebih memudahkan pengumpan (Ikadarny and

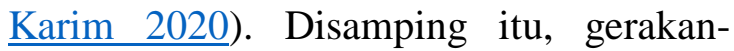
gerakan dasar dalam permainan bolavoli semuanya dilakukan dengan menggunakan lengan sebagai penggerak utama pada proses pelaksanaannya. Oleh karena itu passing bawah yang merupakan salah satu teknik yang paling sering digunakan harus memiliki kemampuan fisik kekuatan otot lengan. Dengan demikian kekuatan otot lengan memiliki kontribusi terhadap kemampuan passing bawah dalam permainan bolavoli.

\section{Ada kontribusi daya tahan otot} tungkai terhadap kemampuan passing bawah dalam permainan bolavoli

Hasil analisis statistik menunjukkan bahwa ada kontribusi daya tahan otot tungkai terhadap kemampuan passing bawah dalam permainan bolavoli pada siswa SMK Negeri 2 Watangsoppeng. Apabila hasil penelitian ini dikaitkan dengan teori dan kerangka pikir yang mendasarinya, maka dalam dasarnya hasil penelitian ini mendukung dan memperkuat teori dan hasil-hasil penelitian terdahulu yang sudah ada. Ini membuktikan bahwa tungkai berfungsi untuk membantu pergerakan dalam pelaksanaan teknik dasar passing bawah. Posisi tungkai dalam permainan bolavoli membentuk sebuah kuda-kuda (Febriani and Rifki 2020) dengan proses setengah jongkok (Herman 2019). Hal ini dilakukan agar supaya proses pelaksanaan pantulan bola pada lengan untuk dapat diarahkan dengan baik. Disamping itu, setiap pemain yang harus bergerak untuk menjemput bola yang datang (Oktariana and Hardiyono 2020) sehingga pemain yang kurang baik dalam daya tahan otot tungkainya, tentu gerakan pada passing bawahnya kurang baik pula. Dengan demikian daya tahan otot tungkai memiliki kontribusi terhadap kemampuan passing bawah dalam permainan bolavoli.

\section{Ada kontribusi koordinasi mata} tangan terhadap kemampuan passing bawah dalam permainan

\section{bolavoli}

Hasil analisis statistik menunjukkan bahwa ada kontribusi koordinasi mata tangan terhadap kemampuan passing bawah dalam permainan bolavoli pada siswa SMK Negeri 2 Watangsoppeng. Apabila hasil penelitian ini dikaitkan dengan teori dan kerangka pikir yang mendasarinya, maka dalam dasarnya hasil penelitian mendukung dan memperkuat teori dan hasil-hasil penelitian terdahulu 
yang sudah ada. Ini membuktikan bahwa koordinasi gerak mata dan tangan adalah yang terjadi dari informasi yang diintegrasikan ke dalam gerak anggota badan. Semua gerakan tangan harus dapat dikontrol dengan penglihatan dan harus tepat sesuai dengan urutan yang direncanakan untuk melakukan passing bawah (Adha 2019). Melakukan passing bawah maupun teknik bolavoli lainnya, semua memerlukan sejumlah input yang dapat dilihat, kemudian input tadi diintegrasikan ke sejumlah input yang dapat dilihat kedalam gerak motorik sebagai output, agar hasilnya merupakan gerakan yang terkoordinasi. Hal ini dapat diuraikan bahwa bola yang datang, pemain harus bergerak untuk mengantisipasi datangnya bola (Asmawi, and Samsudin 2020). Sehingga seorang pemain harus memperhatikan gerak laju bola untuk mempassing dengan baik. Dengan demikian koordinasi mata tangan memiliki kontribusi terhadap kemampuan passing bawah dalam permainan bolavoli.

\section{Ada kontribusi kekuatan otot} lengan, daya tahan otot tungkai, dan koordinasi mata tangan terhadap kemampuan passing bawah dalam permainan bolavoli

Hasil analisis statistik menunjukkan bahwa ada kontribusi kekuatan otot lengan, daya tahan otot tungkai, dan koordinasi mata tangan terhadap kemampuan passing bawah dalam permainan bolavoli pada siswa SMK Negeri 2 Watangsoppeng. Apabila hasil penelitian ini dikaitkan dengan teori dan kerangka pikir yang mendasarinya, pada dasarnya hasil penelitian ini mendukung dan memperkuat teori yang sudah ada. Ini membuktikan bahwa kekuatan otot lengan, daya tahan otot tungkai, dan koordinasi mata tangan sangat mempengaruhi kemampuan passing bawah dalam permainan bolavoli. Kekuatan otot lengan berfungsi sebagai penggerak dalam melaksanakan passing bawah. Gerakan pantulan bola akan terjadi dengan baik bila lengan yang dimiliki seorang pemain ditopan adanya kemampuan fisik kekuatan (Satria 2017). Gerakan-gerakan dasar dalam permainan bolavoli semuanya dilakukan dengan menggunakan lengan sebagai penggerak utama pada proses pelaksanaannya. Oleh karena itu passing bawah yang merupakan salah satu teknik yang paling sering digunakan harus memiliki kemampuan fisik kekuatan otot lengan (Utomo 2019). Sedangkan tungkai berfungsi untuk membantu pergerakan dalam pelaksanaan teknik dasar passing bawah. Posisi tungkai dalam permainan bolavoli membentuk sebuah kuda-kuda dengan proses setengah jongkok. Hal ini dilakukan agar supaya proses pelaksanaan pantulan bola pada lengan untuk dapat diarahkan dengan baik. Disamping itu 
bahwa mereka yang kurang baik dalam daya tahan otot tungkainya, tentu gerakan pada passing bawahnya kurang baik pula. Disaming itu bahwa kemampuan mengkoordinasikan gerak mata dan tangan adalah yang terjadi dari informasi yang diintegrasikan ke dalam gerak anggota badan. Semua gerakan tangan harus dapat dikontrol dengan penglihatan dan harus tepat sesuai dengan urutan yang direncanakan untuk melakukan passing bawah (Saputra and Gusniar 2019). Melakukan passing bawah maupun teknik bolavoli lainnya, semua memerlukan sejumlah input yang dapat dilihat, kemudian input tadi diintegrasikan ke sejumlah input yang dapat dilihat kedalam gerak motorik (Rithaudin and Hartati 2016) sebagai output, agar hasilnya merupakan gerakan yang terkoordinasi secara luwes. Dengan demikian kekuatan otot lengan, daya tahan otot tungkai, dan koordinasi mata tangan memiliki kontribusi terhadap kemampuan passing bawah dalam permainan bolavoli.

\section{Kesimpulan}

Berdasarkan hasil penelitian dan pembahasan yang telah dikemukakan, maka dapat ditarik sebuah kesimpulan sebagai berikut:

1. Kekuatan otot lengan memiliki kontribusi terhadap kemampuan passing bawah dalam permainan bolavoli.

2. Daya tahan otot tungkai memiliki kontribusi terhadap kemampuan passing bawah dalam permainan bolavoli.

3. Koordinasi mata tangan memiliki kontribusi terhadap kemampuan passing bawah dalam permainan bolavoli.

4. Kekuatan otot lengan, daya tahan otot tungkai, dan koordinasi mata tangan memiliki kontribusi terhadap kemampuan passing bawah dalam permainan bolavoli.

\section{Daftar pustaka}

Abrasyi, Rendy, Hernawan, Bambang Sujiono, and Dupri. 2018. "Model Latihan Passing Bawah Bolavoli Pada Siswa Sekolah Menengah Pertama." Journal Sport Area 3(2):168-78.

Adha, Muliadi. 2019. "Kontribusi Koordinasi Mata-Tangan Terhadap Kemampuan Passing BAwah Bolavoli Siswa Ekstrakurikuler SMP Negeri 1 Kampar Kecamatan Kampar Kabupaten Kampar Riau." Skripsi, Progam Pendidikan Jasmani Kesehatan Dan Rekreasi, Fakultas Keguruan Dan Ilmu Pendidikan, Universitas Islam Riau.

Afdi, Rahmat Baitul, Zulman Zulman, and Ali Asmi. 2019. "Pengaruh Model Latihan Passing Terhadap Kemampuan Passing Bawah Dan Passing Atas Pemain Bolavoli." Sport Science 19(1):33-40. doi: 10.24036/jss.v19i1.26.

Atsani, Muhammad Reza. 2020. "Meningkatkan Kemampuan Passing 
Bawah Bolavoli Menggunakan

Metode Bermain." Edu Sportivo,

Indonesian Journal of Physical

Education 1(2):88-96. doi:

https://doi.org/10.25299/es:ijope. 2020

.vol1(2).5592.

Baidawi, Thoriq, and Maidarman. 2019. "Minat Siswa Terhadap Pembelajaran Bolavoli." Jurnal Patriot, Kepelatihan, FIK Universitas Negeri Padang 2(5):1300-1306.

Moch Asmawi, and Samsudin Samsudin. 2020. "Kemampuan Servis Atas Permainan Bola Voli (Studi Eksperimen Model Pembelajaran Dan Koordinasi Mata Tangan)." Jurnal Segar 8(2):68-79. doi: 10.21009/segar/0802.03.

Febriani, Yola, and Muhamad Sazeli Rifki. 2020. "Pengaruh Metode Drills For Game-Like Situation Terhadap Kemampuan Passing Bawah Atlet Bolavoli." Jurnal Stamina 3(6):48198.

Hafiz Nursalam, Ishak Aziz. 2020. "Kontribusi Daya Tahan Kekuatan Otot Tungkai Dan Daya Tahan Kekuatan Otot Lengan Terhadap Kecepatan Renang 100 Meter Gaya Bebas." Jurnal Patriot, Universitas Negeri Padang 2(1):233-43.

Hambali, Sumbara. 2019. "Implementasi Metode Bermain Dalam Pembelajaran Passing Bawah Bola Voli Di Sekolah Dasar." Perspektif Ilmu Pendidikan 33(1):27-32. doi: 10.21009/pip.331.3.

Hamid, Faisol. 2013. "Kontribusi Kekuatan Otot Lengan, Otot Tungkai, Dan Keseimbangan Terhadap Kemampuan Passing Bawah Bolavoli." Bravo's Jurnal, Program Studi Pendidikan Jasmani Dan Kesehatan STKIP PGRI Jombang 1(4):151-67.

Hamzah, Ibnu, Agi Ginanjar, and Anang Setiawan. 2019. "Pengaruh Model Pembelajaran Jigsaw Terhadap Hasil Belajar Passing Bawah Bola Voli." Jurnal Kependidikan Jasmani Dan
Olahraga 3(1):58-63.

Haprabu, Eriek Satya. 2017. "Upaya Meningkatkan Kemampuan Passing Bawah Bola Voli Dengan Menggunakan Media Bola Modifikasi Dan Permainan Sederhana Pada Siswa Kelas V SD Negeri Karang Turi Wonogiri Tahun Ajaran 2016/2017." Jurnal Ilmiah SPIRIT 17(1):61-72.

Hardiansyah, Sefri. 2019. "Kontribusi Daya Tahan Kekuatan Dan Daya Ledak Otot Tungkai Terhadap Kemampuan Tendangan Depan Atlet Pencak Silat Unit Kegiatan Olahraga UNP." Menssana 1(2):61-67.

Herman, Herman. 2019. "Kontribusi Kondisi Fisik Terhadap Kemampuan Passing Bawah Dalam Permainan Bolavoli Pada Siswa Man 2 Kota Makassar." Exercise: Journal of Physical Education and Sport 1(1):34-48. doi: 10.37289/exercise.v1i1.16.

Ihwan, Aktiva Fajar. 2011. "Minat Terhadap Modifikasi Pembelajaran Permainan Bola Voli Pada Siswa Kelas IV, V, Dan VI SD Negeri 01 Sedan Kecamatan Sedan Kabupaten Rembang 2010/2011." DIGILIB UNNES, Local Content Repository 175.

Ikadarny, Ikadarny, and Achmad Karim. 2020. "Kontribusi Koordinasi Mata Tangan, Kekuatan Otot Lengan, Dan Keseimbangan Terhadap Kemampuan Passing Bawah Pada Permainan Bola Voli." Jendela Olahraga 5(1):65. doi: 10.26877/jo.v5i1.4299.

Iskandar. 2016. "Hubungan Antara Kekuatan Otot Dengan Servis Atas Bola Voli Mahasiswa Putra Penjaskes IKIP-PGRI Pontianak." Jurnal Pendidikan Olahraga 5(1):20-28.

Ismoko, Anung Probo, and Pamuji Sukoco. 2013. "Pengaruh Metode Latihan Dan Koordinasi Terhadap Power Tungkai Atlet Bola Voli Junior Putri." Jurnal Keolahragaan 1(1):112. doi: 10.21831/jk.v1i1.2339. 
Jahrir, Andi Sahrul. 2019. "Kontribusi Kekuatan Otot Lengan, Koordinasi Mata Tangan Dan Panjang Lengan Terhadap Kemampuan Passing Bawah Bolavoli Siswa." Exercise: Journal of Physical Education and Sport 1(1):49-67. doi: 10.37289/exercise.v1i1.22.

Juita, Ardiah. 2013. "Kontribusi Daya Ledak Otot Lengan Dan Koordinasi Mata Tangan Terhadap Ketepatan Servis Atas Bolavoli Mahasiswa Pendidikan Kepelatihan Olahraga Universitas Riau." Jurnal Primary Program Studi Pendidikan Guru Sekolah Dasar Fakultas Keguruan Dan Ilmu Pendidikan Universitas Riau 2:25-33.

Kastrena, Ervan, Edi Setiawan, Ihsan Abdul Patah, and Lutfi Nur. 2020. "Pembelajaran Peer Teaching Berbasis Zoom Video Sebagai Solusi Untuk Meningkatkan Hasil Belajar Passing Bawah Bola Voli Saat Situasi COVID-19." Indonesian Journal of Primary Education 4(1):69-75.

Kusnadi, Edi, and Ruslam Abdul Gani. 2020. "Pembelajaran Teknik Passing Bawah Bola Voli Melalui Pendekatan Gaya Mengajar Komando." JPOS (Journal Power Of Sports) 50(February):3-10.

Masrun, Rizki Zam Darmawan Padli Alnedral. 2020. "Kontribusi Antara Motivasi Dan Koordinasi MataTangan Dengan Keterampilan Servis Bawah Bolavoli." Jurnal Patriot 2(3):860-73. doi: 10.4135/9780857020116.n162.

Muhajir, Ahmad. 2007. "Faktor-Faktor Yang Mempengaruhi Minat Siswa Kelas $X$ Dalam Mengikuti Ekstrakurikuler Olahraga Di SMA Islam Sultan Agung I Semarang Tahun Ajaran 2006/2007." DIGILIB UNNES, Local Content Repository.

Mustaqim, Muhammad. 2016. "Upaya Peningkatan Keterampilan Servis Bawah Pembelajaran Bolavoli Mini Melalui Modifikasi Jarak Dan Tinggi
Net Siswa Kelas V SDN Mangli Kaliangkrik Kabupaten Magelang." Journal Of Sport Coaching And Physichal Education.

Nasriani, Anum, and Romi Mardela. 2019.

"Kecepatan Reaksi Dan Koordinasi Mata-Tangan Berhubungan Dengan Kemampuan Smash Bolavoli." Jurnal Patriot, Universitas Negeri Padang 1(3):876-88. doi: https://doi.org/10.24036/patriot.v1i3. 362.

Nurudin, Faqih. 2015. "Hubungan Antara Kekuatan Otot Lengan Dan Koordinasi Mata-Tangan Dengan Kemampuan Passing Bawah Pada Peserta Ekstrakurikuler Bolavoli SMP Negeri 4 Kalasan Sleman." Skripsi, Pendidikan Jasmani Kesehatan Dan Rekreasi, Pendidikan Olahraga, Fakultas Ilmu Keolahragaan, UNiversitas Negeri Yogyakarta.

Oktariana, Dina, and Bayu Hardiyono. 2020. "Pengaruh Daya Ledak Otot Lengan, Daya Ledak Otot Tungkai Dan Kekuatan Otot Perut Terhadap Hasil Smash Bola Voli Pada Siswa SMK Negeri 3 Palembang." Journal Coaching Education Sports 1(1):1324. doi: 10.31599/jces.v1i1.82.

Pasaribu, Ahmad Muchlisisn Natas. 2016.

"Pengaruh Gaya Mengajar Dan Motivasi Belajar Passing Bawah Dalam Permainan Bolavoli Pada Siswa SMP Kelas VIII Tahun 2013/2014." Jurnal Sportif 2(2):8597.

Rithaudin, Ahmad, and Bernadicta Sri Hartati. 2016. "Upaya Meningkatkan Pembelajaran Passing Bawah Permainan Bola Voli Dengan Permainan Bola Pantul Pada Siswa Kelas IV SD Negeri Glagahombo I Tempel Sleman Yogyakarta." Jurnal Pendidikan Jasmani Indonesia 12(1):51-57.

Sahabuddin. 2018. "Pengaruh Latihan Model Pembelajaran Pukulan Bola Ke Tembok Terhadap Kemampuan Servis Atas Bolavoli Pada Siswa 
SMK Negeri 2 Makassar.'

Competitor: Jurnal Pendidikan

Kepelatihan Olahraga, FIK UNM 10(1):28-36. doi:

https://doi.org/10.26858/com.v10i1.8 480.

Sahabuddin. 2019. "Pengaruh Latihan Knee Tuck Jump Dan Latihan Box Jump Terhadap Peningkatan Smash Bolavoli Ditinjau Daya Ledak Tungkai." SPORTIVE: Journal Of Physical Education, Sport and Recreation 3(1):38. doi: 10.26858/sportive.v3i1.16858.

Sahabuddin, Hikmad Hakim, and Ahmad Rum Bismar. 2020. "Analisis Kinerja Guru Pendidikan Jasmani Olahraga Dan Kesehatan Terhadap Motor Ability Dan Hasil Belajar Pada Siswa SD Negeri Di Kabupaten Pinrang." Ejurnal.Ubharajaya.Ac.Id 1(1):3548. doi: https://doi.org/10.31599/jces.v1i1.84.

Saptiani, Dela, Sugiyanto Sugiyanto, and Syafrial Syafrial. 2019. "Hubungan Kekuatan Otot Lengan Dan Koordinasi Mata Tangan Terhadap Akurasi Servis Atas Bola Voli Pada Peserta Putri Ekstrakurikuler Di Sman 2 Seluma." Kinestetik 3(1):4250. doi: 10.33369/jk.v3i1.8810.

Saputra, Deka Ismi Mori, and Gusniar Gusniar. 2019. "Meningkatkan Hasil Belajar Passing Bawah Bola Voli Melalui Bermain Melempar Bola." Gelanggang Olahraga: Jurnal Pendidikan Jasmani Dan Olahraga (JPJO) 3(1):64-73. doi: 10.31539/jpjo.v3i1.862.

Saputra, Rey Junay Hasan. 2018. "Minat Siswa Sma Kelas X Pada Cabang Olahraga Futsal, Bulutangkis, Bolavoli, Dan Bolabasket Di Kecamatan Magetan, Kabupaten Magetan." Skripsi Pendidikan Jasmani Kesehatan Dan Rekreasi Universitas Negeri Yogyakarta (UNY) 1-89.

Satria, Johan Andika. 2017. "Hubungan Antara Kekuatan Otot Lengan Dan
Kecepatan Reaksi Tangan Dengan Kemampuan Passing Bawah Pada Bolavoli Siswa Putra Kelas VIII C SMPN 1 Semen Kabupaten Kediri Tahun Pelajaran 2016/2017." Artikel Skripsi, Universitas Nusantara PGRI Kediri 1-9.

Satria, M. Haris. 2019. "Pengaruh Latihan Kekuatan Jari-Jari Tangan Terhadap Peningkatan Kemampuan Passing Atas Dalam Permainan Bolavoli." Journal Sport Area 4(1):230-39. doi: https://doi.org/10.25299/sportarea.20 19.vol4(1).2349.

Utomo, Riska Bhakti. 2019. "Kontribusi Kekuatan Otot Lengan, Kecepatan Reaksi, Dan Kelincahan Terhadap Passing Bawah Pada Permainan Bolavoli (Studi Pada Atlet Bolavoli Putera Universitas Negeri Surabaya)." Jurnal Pendidikan Kepelatihan Olahraga FIK Unesa 10(2):1-14.

Yudhianto, Arindra, and Sasminta christina yuli Hartati. 2013. "Pengaruh Model Pembelajaran Kooperatif Tipe Student Teams Achievement Division (Stad) Terhadap Hasil Belajar Servis Bawah Bolavoli." Jurnal Pendidikan Olahraga Dan Kesehatan 1(2):30710.

Zakaria, Gumilar, Deni Mudian, and Pulung Riyanto. 2018. "Pengaruh Latihan Plyometrics Jum To Box Terhaap Peningkatan Power Tungkai Siswa Kelas X Pada Permainan Bolavoli." BIOMARTIKA, Jurnal Ilmiah FKIP Universitas Subang $5(1)$. 